\title{
Driving public sector innovation using big and open linked data (BOLD)
}

\author{
Marijn Janssen $^{1}$ - David Konopnicki ${ }^{2}$. Jane L. Snowdon ${ }^{3}$ • Adegboyega Ojo ${ }^{4}$
}

Published online: 13 March 2017

(C) Springer Science+Business Media New York 2017

\section{Introduction}

Innovation in government is about finding new ways to improve society, the government itself and the relationship between the government and the public. Many of such innovations are driven by the availability of Big and Open Linked Data (BOLD) (Janssen and Kuk 2016), the Internet of Things (IoT) and the resulting datafication of our society. Data-driven innovation can result in a dramatic transformation of public sector systems and can create societal benefits like less pollution, fewer traffic jams, improved tracking of disease outbreaks, greater energy efficiency, new agriculture services, novel applications to transform citizen experience interacting online with government, and lower costs. Big and open data play a pivotal role in this transformation and collecting, combining and sharing data from various sources has become an important means for public-sector innovation.

Marijn Janssen

M.F.W.H.A.Janssen@tudelft.nl

David Konopnicki

davidko@il.ibm.com

Jane L. Snowdon

snowdonj@us.ibm.com

Adegboyega Ojo

adegboyega.ojo@insight-centre.org

1 Faculty of Technology, Policy and Management, Delft University of Technology, Delft, The Netherlands

2 IBM Haifa Research Laboratory, Haifa, Israel

3 Watson Health Partnerships, IBM Corporation, Armonk, NY, USA

4 The Insight Centre for Data Analytics, National University of Ireland, Galway, Republic of Ireland
BOLD is a global phenomenon driven by the need to boost innovation, create transparency and improve accountability (Bertot et al. 2010; Lourenço 2015). Adoption proves to be challenging (Zuiderwijk et al. 2015). Achieving the BOLD objectives might require tradeoffs such as transparency versus privacy as a competing value (Janssen and Van den Hoven 2015) and a data protection act might prevent sharing (van Loenen et al. 2016). Linking and analyzing data originating from a variety of sources can be applied in various domains, like providing real-time weather, pollution and traffic information, but also for enforcement and fraud detection, creating transparency, making cities smarter, improving a country's competitiveness, improving decision- and policy-making and responding better in crisis management. At the local level this is often denoted as smart cities, in which all kinds of apps can assist in monitoring, analyzing and visualizing social, economic and environmental phenomena (Jaakola et al. 2015). Nevertheless there is no consensus about what smartness is (Gil-Garcia et al. 2016). Smartness encompasses various aspects including data, technology, processes and people. Data should be used to empower persons resulting in 'smart citizens'.

Instead of reinforcing current processes, big and open data should result in open government (Luna-Reyes et al. 2014). Not only should data be published, but it should be actively sought for feedback to improve the government. The publishing of government data could have far-reaching effects on the public sector. Furthermore the availability of a vast amount of data can have a profound influence on policy-making. Data can be used by governments and the public for modelling, understanding policy implications, and supporting policy decisions. For example, Data.gov is the U. S. federal government's open data site, which aims to make government more open and accountable, thereby increasing citizen participation in government, creating opportunities for economic development, and informing decision making in 
both the private and public sectors. Innovation of governments is likely to be driven by external parties like enterprises and citizens combined with internally driven processes. However, there is paucity of systematic research in this area.

This special issue of ISF shows advances in the emerging issues of BOLD in public administration. The 9 papers included contribute to the creation of a common body of knowledge for this multi-disciplinary field of study. In this editorial, we start by discussing the technology innovation capabilities driving public sector innovation. We focus on those aspects and capabilities that are unique for data-driven innovation. Thereafter we provide a list of factors influencing and driving data-driven innovation. A look at new organizational arrangements for public sector innovation, which are becoming more and more dependent on the interaction between public and private parties, follows. The role of new organizational arrangements for creating data-driven public sectors innovation is presented. Four forms of data-driven innovation are identified by grouping innovation initiatives along the level of participation and number of users. The overview of the nine papers in this special issue is presented thereafter. Finally, conclusions are drawn and further research suggestions are given.

\section{Technology innovation capabilities}

Data-driven innovations need an infrastructure for creating value from data (Jetzek 2016). Big data can be generated by integrating many datasets from multiple structured and unstructured sources, and consists of a range of techniques used to manage and analyze data, while also incorporating data increasingly available through government open data initiatives. Research in open data has shown that quality rather than quantity of data matters for service and digital innovation (Kuk and Davies 2011).

There are many definitions and characterizations of big data (Cai and Zhu 2015; De Mauro et al. 2015). The frequently recognized elements are Volume, Velocity, Variety, Veracity, and Value. Whereas big data is characterized by the Vs of data, open data enables its access by a large audience (Janssen et al. 2015). Data can be downloaded from open data portals or used through data streaming (Attard et al. 2015). At the same time tapping into these vast amounts of data provides the potential to improve activities of public organizations (Janssen et al. 2017). Open data can bridge the traditional separation between public organizations, enterprises and users. In the current digital age, citizens are expecting more effective and responsive government services. In addition, the transparency demands on governments are mandating better accountability and elevated performance. Governments need to deliver policies that achieve sustainable outcomes while reducing operational costs.

Governments have become aware that they are operating within ecosystems of public and private actors. By opening data, the public gets access to data which provides countless opportunities for economic, political, scientific, and social initiatives and innovation. At the same time governments are looking to harness data beyond their traditional borders by analyzing data from a variety of social media channels, making sensors of us all. The need to effectively utilize data from a variety of sources including the social web is driving the development of new government-citizen and governmentemployee applications and the generation of new data analytics toolsets.

Sensor-rich devices, smart phones, wearables, and even cars generate data about persons and their environment and result in the creation of the Internet of Things (IoT). Everyday life objects become equipped with microcontrollers and transceivers for digital communication, enabling them to measure and communicate with other systems and their users (Atzori et al. 2010). IoT enables all kinds of new home appliances, surveillance cameras, monitoring sensors, actuators, displays, vehicles, and so on (Zanella et al. 2014). IoT enables the development of a number of applications that make use of the potentially enormous amount and variety of data generated by such objects to provide new services to citizens, companies, and public administrations.

Big data, data analytics, open data and IoT integrates several fields which adds to the complexity. Therefore, we seek new innovative capabilities enabled by these technologies. These innovative capabilities can be grouped by looking at the data cycle.

- Collecting of data: IoT requires the ability to collect data at low costs. The more devices generate data, the more data can be collected and the more insight can be created. Often IoT devices are owned by various parties which complicates the collecting of data, as for example sensors on smart phones, smart energy meters or tracking devices are owned by citizens.

- Opening and sharing of data: The ability to access data is a crucial one for enabling innovation. Data is collected by various organizations including governments, companies and citizens, and the ability to gain access to data is a condition for innovation. The level of openness may vary; more and more companies share data with their partners, but not with everybody.

- Combining data: The ability to link, relate, fuse and combine data from different sources creates the actual value. Once data can be accessed, the various datasets can be combined. This can result in novel applications.

- Analyzing data: the ability to analyze data for new insights and applications results in innovation and action-oriented 
decision-making. Often statistics and advanced visualization techniques play a role in analyzing data.

These four technology innovation capabilities are specific to data-driven innovation. Also other capabilities are needed for enabling innovation, like the ability to involve others and manage the innovation process. The work of Zeleti and Ojo (2017) in this issue focuses on developing capabilities for data-driven innovation.

\section{Factors influencing data-driven innovation}

The papers in this special issue show that a large number of factors influence public sector innovation. Public sector innovation has already gained attention for a very long time. There are many government policies and programs to support the process of technology and innovation (Wonglimpiyarat 2014). What is new is the focus on data enabling novel types of applications. For example Klievink et al. (2017) found in their paper in this special issue that an institutional setting might hinder big data adoption and, due to possible risks, big data is not used to its full potential. From the papers of this special issue, a large number of factors appeared to influence data-driven public sector innovation as shown in Table 1. The factors were categorized along four dimensions: strategic and political, organizational, data governance, and technical. Although the categories appear generic, the factors are specific for this domain of datadriven innovation. The factors are multi-faceted and interdependent and can be used by governments and other parties to drive data-driven innovation. The limited understanding of the factors make it hard to steer data-driven innovation and more research in this area is needed.

Hurley and Hult (1998) analyzed innovation activities and found that both structural and process characteristics influence innovation. In Table 1 most of the factors are structural factors and only some focus on the process. In this special issue Viale Pereira et al. (2017) investigate the process of value creation in smart cities and show that the drivers are diverse and important. In addition, cultural factors, like a risk-averse culture, influence the innovation process. In innovation, bureaucratic and political factors are found to be more dominant than technological, economic and politico-economic perspectives (Gonzalez-Zapata and Heeks 2015). The links between transparency, openness, accountability, participation, and trust and data-driven innovation are often vague and unclear, as shown in the paper of Dwivedi et al. (2017) of this special issue. This is due to the high dependency between the concepts, but also due to the different conceptualizations. More insights into these factors and the influence of these factors are needed to understand what drives data-driven public sector innovation.

\section{Organizing data-driven innovation}

Whereas public innovation is driven by public organizations, this might not be the case for data-driven public innovation. Often private organizations and citizens play a major role in innovating government and government transformation. This demands new organizational forms and this special issue shows that there are new ones emerging. For example parties external to the government have started using data opened by government to create new apps and services. These business models intermediate between data providers and users (Janssen and Zuiderwijk 2015). Hackathons have been organized in which data is provided to groups, to derive innovative solutions within a short time frame. A hackathon's duration can vary from half a day to a couple of days and also the number of persons involved can vary from a few to hundreds. Hackathons can be an excellent way to crowdsource a solution. Living labs are environments that support public open innovation processes (Gascó 2017). These innovation labs enable public organizations to meet with private sector organizations and to derive jointly creative solutions. Another organizational form is named data collaborative, in which public and private organizations work together to solve societal issues (Susha et al. 2017). Data collaboratives are led and setup by private parties to help society, but at the same time solving societal problems can be beneficial for their image and can help them to innovate. Agile innovation management consists of a combination of agile software development and modular acquisition approaches to innovate digital service delivery in government (Mergel 2016). Often new independent organizational units equipped with fast reacting teams are used for agile software development. Often users are part of these teams to ensure the creation of user-centric applications.

Social media and crowdsourcing often play a role in innovation (Criado et al. 2013). Arranging the governance of these teams are challenging and it is found that public governance and innovation co-evolve (Scupola and Zanfei 2016). A greater distribution of knowledge and innovation across different organizational levels within public administrations is to be found necessary (Scupola and Zanfei 2016). Also the involvement of people vary over time.

The bottom line of these new organizational forms is to mobilize society as partners willing to share their data, conduct analyzes and in this way contribute to improve the government and to solve societal problems. Such innovation is driven externally to the government. However, most governments are not prepared to innovate in this way. Old government structures need to be changed and a shift from inwardlooking towards outwards-looking is necessary. Trust among parties is a prerequisite to make this work. Policies providing incentives for collaboration and to organize collaboration between public and private actors can drive this kind of innovation. 
Table 1 Overview of factors driving and influencing data-driven innovation

\begin{tabular}{ll}
\hline Categories & Factors \\
\hline Strategic and political & Type of public values targeted (efficiency, effectiveness, transparency, accountability or engagement) \\
Type of societal problem addressed (different domains including smart cities) \\
Data sharing licenses (enabling or constraining the reuse of data) \\
Culture enabling or blocking innovation (risk-averse behavior, enabling collaboration with others) \\
Resources and budget (making available human resources, money and other means for innovation) \\
Incentives for stimulating data-driven innovation \\
Organizational form of innovation (hackathons, data collaborative, living labs) \\
Public-private collaboration (parties involved) \\
Division of costs and benefits \\
Potential and actual risks (misuse, privacy violation, racial profiling, sensitive data sharing etc.) \\
Trust among stakeholders (influencing willingness to collaborate) \\
Capabilities and knowledge of staff (for being able to innovate using data) \\
Project management (ability to manage the innovation process, to involve other parties etc.) \\
Access to data (open, semi-open or closed access) \\
Data quality (accuracy, veracity, completeness etc.) \\
Ability to reuse data \\
Ability to process and share data \\
Local and country data privacy and access regulations \\
Technology readiness \\
Systems \\
Availability of supporting infrastructure (programming environment, data analytics software, cloud, etc.)
\end{tabular}

\section{Data-driven innovation types}

Innovation is a disruptive force worldwide. At national and local levels and by governments and businesses, new applications are developed based on new technological capabilities. The "let a thousand flowers bloom" innovation strategy is often followed where many innovative ideas are developed, while only a few scale up from small to large once a clear value generation mechanism is developed. This often results in mimicking successful innovations by other governments (mimetic isomorphism of DiMaggio and Powell (1983)). Many governments have similar innovative applications nowadays.

Sometimes the innovations are strictly guided by governments in which policy is developed to guide the efforts, whereas in other situations no government at all is involved and citizens or companies are leading. The advantages of a bottom-up approach include better support of local needs, 'natural selection' of practices that are mimicked by others, higher user acceptance, whereas the disadvantages are the increasing fragmentation and lack of standard development (van Veenstra and Janssen 2012). Also the number of bottom-up initiatives is immense resulting in many innovations from which a few really add value and are sustainable.

The innovation practices can be classified by looking at the process of innovation and by the resulting products. This classification results in Fig. 1 in which the y-axis refers to the involvement of public-private parties in the innovation process and the $\mathrm{x}$-axis shows the usage of the resulting product. The level of involvement in innovation can vary. Innovation might be driven internally in the government or completely left to private parties, like companies and citizens. The papers in this editorial show that often a combination is used and the trend is that both public and private parties are involved in the innovation process. The resulting outcomes of the innovation process might be used by large volume of users (like a weather or pollution) app or one-time use for making a policy decision (the location of a new energy plant). Apps supporting large volumes of users are often operated by private parties, whereas lower volumes are often used by government for their policy-making activities.

\section{Papers overview}

The first paper "Driving Innovation through Big Open Linked Data (BOLD): Exploring Antecedents using Interpretive Structural Modelling" by Dwivedi et al. (2017) provides a comprehensive overview of factors influencing big and open data. Using interpretive structural modelling the authors analyze the interrelationships between antecedents of innovation through BOLD. The work revealed that technical infrastructure, data quality, and external pressure are the foundations for data-driven innovation of governments.

In the paper "Delivering Public Value through Open Government Data Initiatives in a Smart City Context" by Viale Pereira et al. (2017) the effect of open data on value creation in smart cities is investigated. The authors develop a conceptual model for understanding value creation by open data. The set of identified value generators are efficiency, 


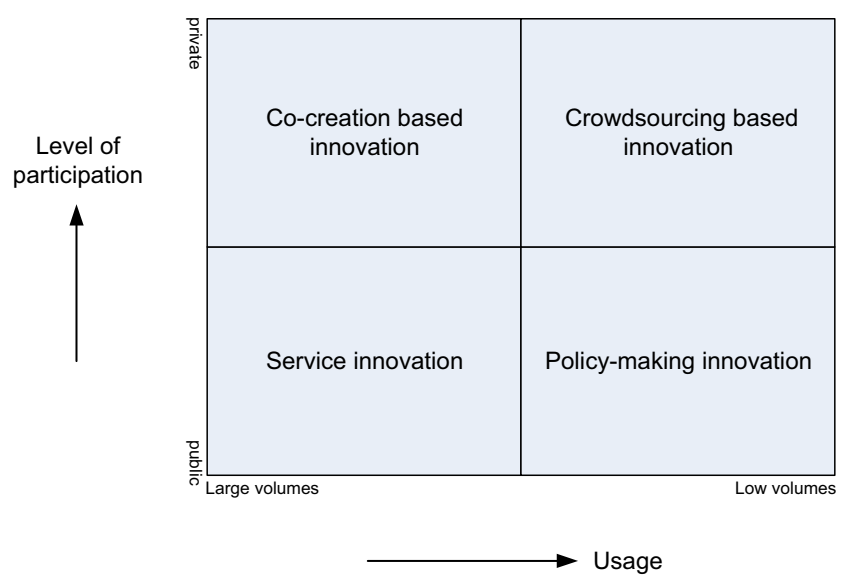

Fig. 1 Overview of data-driven innovation types

effectiveness, intrinsic enhancements, transparency, participation, and collaboration. The authors demonstrate that open data initiatives contribute to enhance the delivery of public value in economic, strategic, political, stewardship and quality of life.

The opinions, wishes, and complaints of citizens and other stakeholders should be integrated in public innovation processes. The sheer volume of data requires that data be processed without human intervention. Baur (2017) followed a design science approach for developing an artifact able to handle large amounts of foreign-language user-generated content in his paper named "Harnessing the social web to enhance insights into people's opinions in business, government and public administration." By employing the framework, government can make use of multi-language, multi-source social media content.

Data integration of user activities in social networks with government applications can enhance government decisionmaking. In the paper "Integrating Data from User Activities of Social Networks to Public Administrations" by Rosenberger et al. (2017) the aim is to reduce the complexity of integrating input from multiple, different social networks. The use of data should be used in the innovation process. Integration should enable governments to get a better overview of social media.

In the paper "Big Data in the Public Sector: Uncertainties and Readiness" by Klievink et al. (2017) an assessment framework for evaluating public organizations' big data readiness is derived. The authors found that although the technical capabilities might be available, the institutional setting might hinder big data adoption. The opportunities presented by big data might not be accomplished due to risks provided by the use of big data.

Disclosing data using government portals can enable public engagement in policy making. The paper "Open Data and its Usability: An Empirical View from the Citizen's Perspective" by Weerakkody et al. (2017) investigate predictors for the acceptance and use of public sector open data. For this, Rogers' diffusion of innovations theory (DOI) is enhanced. The authors found that relative advantage was the strongest predictor of behavioral intention and relative advantage, compatibility, and observability positively and significantly predicted behavioral intentions of citizens to use open data.

Crowdsourcing has become an increasingly attractive practice for public sector to tap into the creativity and innovation capacity of the crowd. In the paper "Estimating Participants for Knowledge-intensive Tasks in a Network of Crowdsourcing Marketplaces" by Gong (2017) a network of crowdsourcing marketplaces is envisioned for efficient knowledge-intensive crowdsourcing and engagement. Using simulation the author shows that crowdsourcing in the marketplace can result in higher levels of task success. This finding suggests that networked crowdsourcing marketplaces are expected to provide access to a greater diversity of expertise and a larger crowd.

Linked Data is a favored approach to data integration as it enables easy sharing, combining and reusing data. In the paper "Challenges and Opportunities in Renovating Public Sector Information by Enabling Linked Data and Analytics" by Mouzakitis et al. (2017) the potential of linked data is analyzed. The authors proposed a technical framework that aims to hide the underlying complexity of linked data, while maintaining and promoting the interlinking capabilities. The advantages for users is that the framework can be used in order to minimize the required adoption effort of linked data technology, and offer more options and flexibility to the end-users of open data.

Capabilities are needed to generate value from open data. Zeleti and Ojo's (2017) paper "Open Data Value Capabilities Architecture" creates a framework for organizations to identify, map, develop and plan open data value capabilities. They argue that managers should identify what individual, process, organization, IT-infrastructure, technological infrastructure, and management capabilities are required for generating data. Their case studies showed that government often focuses on capabilities like 'generating data,' 'data processing' and 'publishing solution.'

\section{Conclusions}

Innovation in a data-driven government is centered around collaboration between the government, the private sector and the public to find new innovative applications and solutions. These innovations can help to create higher levels of efficiency, transparency, accountability, services levels and trust in government. Data-driven innovation requires technological innovation capabilities needed for collecting, opening and sharing, combining, and analyzing data.

Data-driven public sector innovation is a complex field in which many stakeholders are involved. For this, new organizational forms (e.g. hackathons, living labs and data 
collaboratives) are emerging which can result in new infomediary business models. These developments show a shift toward networked arrangements involving public and private parties. A variety of factors influence and drive public sector innovation which can be grouped into strategic and political, organizational, data governance and technical dimensions. Driving data-driven innovation requires that government provide more attention to information management and data governance. This will enable data reuse. Furthermore, incentives for stimulating innovation and conditions should be in place to enable innovation. The influence of these interdependent factors is hardly understood, which makes it difficult for government to steer the innovation process.

This special issue contains nine papers providing different views and new insights in the field of data-driven public sector innovation. The innovation approaches can be captured by looking at the differences in the level of participation in the innovation process and usage of the resulting outcomes. Public or private organizations or both can be involved. The resulting innovation can lead to services broadly used by the public or to insights that can influence policy-making decisions.

\section{References}

Attard, J., Orlandi, F., Scerri, S., \& Auer, S. (2015). A systematic review of open government data initiatives. Government Information Quarterly, 32(4), 399-418.

Atzori, L., Iera, A., \& Morabito, G. (2010). The internet of things: A survey. Computer Networks, 54(15), 2787-2805. doi:10.1016/j. comnet.2010.05.010.

Baur, A. W. (2017). Harnessing the social web to enhance insights into people's opinions in business, government and public administration. Information Systems Frontiers, 19(2). doi:10.1007/s10796-016-9681-7.

Bertot, J. C., Jaeger, P. T., \& Grimes, J. M. (2010). Using ICTs to create a culture of transparency: E-government and social media as openness and anti-corruption tools for societies. Government Information Quarterly, 27, 264-271.

Cai, L., \& Zhu, Y. (2015). The challenges of data quality and data quality assessment in the big data era. Data Science Journal, 14, 2.

Criado, J. I., Sandoval-Almazan, R., \& Gil-Garcia, J. R. (2013). Government innovation through social media. Government Information Quarterly, 30(4), 319-326. doi:10.1016/j. giq.2013.10.003.

De Mauro, A., Greco, M., \& Grimaldi, M. (2015). What is big data? A consensual definition and a review of key research topics. Paper presented at the AIP Conference Proceedings.

DiMaggio, P. J., \& Powell, W. W. (1983). The iron cage revisited: Institutional isomorphism and collective rationality in organizational fields. American Sociological Review, 48(2), 147-160.

Dwivedi, Y. K., Janssen, M., Slade, E. L., Rana, N. P., Weerakkody, V., Millard, J., et al. (2017). Driving innovation through big open linked data (BOLD): Exploring antecedents using interpretive structural modelling. Information Systems Frontiers, 19(2). doi:10.1007/s10796-016-9675-5.
Gascó, M. (2017). Living labs: Implementing open innovation in the public sector. Government Information Quarterly. doi:10.1016/j. giq.2016.09.003.

Gil-Garcia, J. R., Zhang, J., \& Puron-Cid, G. (2016). Conceptualizing smartness in government: An integrative and multi-dimensional view. Government Information Quarterly, 33(3), 524-534. doi:10.1016/j.giq.2016.03.002.

Gong, Y. (2017). Estimating participants for knowledge-intensive tasks in a network of crowdsourcing marketplaces. Information Systems Frontiers, 19(2). doi:10.1007/s10796-016-9674-6.

Gonzalez-Zapata, F., \& Heeks, R. (2015). The multiple meanings of open government data: Understanding different stakeholders and their perspectives. Government Information Quarterly, 32(4), 441-452. doi:10.1016/j.giq.2015.09.001.

Hurley, R. F., \& Hult, G. T. (1998). Innovation, market orientation and organization learning: An integration and empirical examination. Journal of Marketing, 62(3), 42-54.

Jaakola, A., Kekkonen, H., Lahti, T., \& Manninen, A. (2015). Open data, open cities: Experiences from the Helsinki metropolitan area. Case Helsinki region Infoshare www.Hri.Fi. Statistical Journal of the IAOS: Journal of the International Association for Official Statistics, 31(1), 117-122. doi:10.3233/SJI-150873.

Janssen, M., \& Kuk, G. (2016). Big and open linked data (BOLD) in research, policy, and practice. Journal of Organizational Computing and Electronic Commerce, 26(1-2), 3-13. doi:10.1080 /10919392.2015.1124005.

Janssen, M., \& Van den Hoven, J. (2015). Big and open linked data (BOLD) in government: A challenge to transparency and privacy? Government Information Quarterly, 32, 363-368. doi:10.1016/j. giq.2015.11.007.

Janssen, M., \& Zuiderwijk, A. (2015). Infomediary business models for connecting open data providers and users. Social Science Computer Review. doi:10.1177/0894439314525902.

Janssen, M., Matheus, R., \& Zuiderwijk, A. (2015). Big and open linked data (BOLD) to create smart cities and citizens: Insights from smart energy and mobility cases. In E. Tambouris, M. Janssen, H. J. Scholl, M. A. Wimmer, K. Tarabanis, M. Gascó, B. Klievink, I. Lindgren, \& P. Parycek (Eds.), Electronic government (Vol. 9248, pp. 79-90). Thessaloniki: Springer International Publishing.

Janssen, M., van der Voort, H., \& Wahyudi, A. (2017). Factors influencing big data decision-making quality. Journal of Business Research, $70,338-345$.

Jetzek, T. (2016). Managing complexity across multiple dimensions of liquid open data: The case of the Danish basic data program. Government Information Quarterly, 33(1), 89-104.

Klievink, B., Romijn, B.-J., Cunningham, S., \& De Bruijn, H. (2017). Big data in the public sector: Uncertainties and readiness. Information Systems Frontiers, 19(2). doi:10.1007/s10796-016-9686-2.

Kuk, G., \& Davies, T. (2011). The roles of agency and artifacts in assembling open data complementarities. Shanghai: Paper presented at the Thirty Second International Conference on Information System.

van Loenen, B., Kulk, S., \& Ploeger, H. (2016). Data protection legislation: A very hungry caterpillar: The case of mapping data in the European Union. Government Information Quarterly, 33(2), 338 345. doi:10.1016/j.giq.2016.04.002.

Lourenço, R. P. (2015). An analysis of open government portals: A perspective of transparency for accountability. Government Information Quarterly, 32(3), 323-332. doi:10.1016/j. giq.2015.05.006.

Luna-Reyes, L. F., Bertot, J. C., \& Mellouli, S. (2014). Open Government, Open Data and Digital Government. Government Information Quarterly, 31(1), 4-5.

Mergel, I. (2016). Agile innovation management in government: A research agenda. Government Information Quarterly, 33(3), 516-523. doi:10.1016/j.giq.2016.07.004. 
Mouzakitis, S., Papaspyros, D., Petychakis, M., Koussouris, S., Zafeiropoulos, A., Fotopoulou, E., et al. (2017). Challenges and opportunities in renovating public sector information by enabling linked data and analytics. Information Systems Frontiers, 19(2). doi:10.1007/s10796-016-9687-1.

Rosenberger, M., Lehrer, C., \& Jung, R. (2017). Integrating data from user activities of social networks into public administrations. Information Systems Frontiers, 19(2). doi:10.1007/s10796-016-9682-6.

Scupola, A., \& Zanfei, A. (2016). Governance and innovation in public sector services: The case of the digital library. Government Information Quarterly, 33(2), 237-249. doi:10.1016/j. giq.2016.04.005.

Susha, I., Janssen, M., \& Verhulst, S. (2017). Data Collaboratives as a New Frontier of Cross-Sector Partnerships in the Age of Open Data: Taxonomy Development. Paper presented at the Proceedings of the 50th Hawaii International Conference on System Sciences.

Van Veenstra, A. F., \& Janssen, M. (2012). Policy implications of topdown and bottom-up patterns in E-government infrastructure development. In T. M. Egyedi, \& D. C. Mehos (Eds.), Inverse infrastructures: disrupting networks from below (pp. 223-238). Cheltenham: Edward Elgar Publishing.

Viale Pereira, G., Macadar, M. A., Luciano, E. M., \& Testa, M. G. (2017). Delivering public value through open government data initiatives in a Smart City context. Information Systems Frontiers, 19(2). doi:10.1007/s10796-016-9673-7.

Weerakkody, V., Irani, Z., Kapoor, K., Sivarajah, U., \& Dwivedi, Y. K. (2017). Open data and its usability: An empirical view from the Citizen's perspective. Information Systems Frontiers, 19(2). doi:10.1007/s10796-016-9679-1.

Wonglimpiyarat, J. (2014). Innovative policies to support technology and ICT development. Government Information Quarterly, 31(3), 466475. doi:10.1016/j.giq.2013.12.005.

Zanella, A., Bui, N., Castellani, A., Vangelista, L., \& Zorzi, M. (2014). Internet of things for smart cities. IEEE Internet of Things Journal, 1(1), 22-32. doi:10.1109/JIOT.2014.2306328.

Zeleti, F. A., \& Ojo, A. (2017). Open data value capability architecture. Information Systems Frontiers, 19(2). doi:10.1007/s10796-0169711-5.

Zuiderwijk, A., Janssen, M., \& Dwivedi, Y. K. (2015). Acceptance and use predictors of open data technologies: Drawing upon the unified theory of acceptance and use of technology. Government Information Quarterly, 32(4), 429-440.

Dr. Marijn Janssen is full Professor in ICT \& Governance and head of the Information and Communication Technology section of the Technology, Policy and Management Faculty of Delft University of Technology. His research interests are in the field of orchestration, (shared) services, intermediaries, big and open linked data (BOLD) and infrastructures within constellations of public and private organizations. He was involved in EU funded projects in the past (a.o. EGovRTD2020, eGovPoliNet and Engage) and is involved in H2020 OpenGovIntelligence and VRE4EiC project. Dr. Janssen serves as co-editor-in-chief of Government Information Quarterly and is conference chair of IFIP EGOV conference series. He was ranked as one of the leading egovernment researchers in a survey in 2009, 2014 and 2016. More information: www.tbm.tudelft.nl/marijnj.
Dr. David Konopnicki manages the Information Retrieval and Text Analytics group in IBM Research-Haifa and has been involved in Unstructured Content Analytics both from a theoretical and a practical point of view: in the academia, David developed search systems for the early web. In the IBM Software Group and in IBM Research, David has been leading a variety of projects: development of large-scale full-text search engines, building customer profiles from enterprise and social media sources, massive scale analytics with applications to telco companies and more. More recently, David is leading the research of Affective Computing technologies with goal of augmenting Cognitive Computing through measurement, simulation and understanding of human emotions. David is an IBM Master Inventor and holds a $\mathrm{PhD}$ degree in Computer Science from the Technion, Haifa.

Dr. Jane L. Snowdon is Director of Watson Health Partnerships at IBM. She is responsible for business development and execution of Watson Health partnerships across state, federal and global government. Prior to this role, Jane was Chief Innovation Officer, IBM Federal, where she defined and drove strategy, and designed new solutions that addressed defense, civilian and healthcare client mission requirements through innovation and technology adoption. Jane also served as Director of the IBM Federal Cloud Innovation Center in Washington DC. Jane held management and technical roles at IBM T. J. Watson Research Center for over twenty years where she developed and applied novel mathematical models to solve business problems in the manufacturing, energy, and travel and transportation industries. Jane currently serves on the Advisory Board of Georgia Tech and is a past board member of the Intelligence and National Secuirty Alliance (INSA) Council on Technology and Innovation, the Center of Innovation and Entrepreneurship at George Mason University, and Penn State College of Engineering. Jane received her Ph.D. in Industrial and Systems Engineering from the Georgia Institute of Technology, a M.S. degree in Industrial and Operations Engineering from the University of Michigan, and a B.S. degree with distinction in Industrial and Management Systems Engineering from the Pennsylvania State University. She is a Senior Member of IIE, IEEE, and a Member of ACT-IAC, AFCEA, AMIA, CASE, INFORMS, NYAS, SWE, WIT, and WITI. Jane has published more than sixty articles in mathematics, computer science, and engineering literature. She is a recognized thought leader who frequently speaks on the future of information technology at conferences and universities.

Dr. Adegboyega Ojo is Senior Research Fellow at the Insight Centre for Data Analytics, National University of Ireland Galway (NUIG). He leads the E-Government Group at Insight Centre, serves as Adjunct Lecturer at the College of Engineering and Informatics and also teaches the postgraduate module on Technology Strategy and Innovation at the J. E. Cairnes School of Business \& Economics, NUIG. He received his Bachelors and $\mathrm{PhD}$ from the University of Lagos. His current research interests include data driven innovations in government, Open data policies and Infrastructures, data analytics and governance of smart cities. His work has been published in Government Information Quarterly (GIQ), the French Journal "Hermés, La Revue", Information Polity Journal, and Journal of Open and Distance Learning. He has also served as Guest Editor for the GIQ and as editors for conference proceedings. Adegboyega has won best paper awards and is a member of the editorial boards of GIQ and International Journal of Public Administration in the Digital Age (IJPADA). 